\title{
DIE KERK, DIE EENHEID EN DIE GRENS VAN DIE KERK.
}

\section{Wat is die kerk?}

Ons begin met die vraag te stel: Wat is die kerk? Dit is 'n vraag wat nie maklik en eenvoudig beantwoord kan word nie. Dis besonder moeilik om 'n afdoende definisie te gee van wat die kerk is. Hiervoor kan daar verskillende redes opgenoem word. Die kerk het nic deur menslike toedoen tot stand gekom nie. Dis nie 'n menslike stigting of organisasie nie, al bestaan die kerk in die empiriese wêreld as 'n gemeenskap van mense. Dit is dus nie 'n suiwer aardse verskyning wat uit die wêreld en uit die mense ontspring het en assulks beskrywe kan word nie. Dit het ontstaan deur 'n goddelike sameroeping. Die bestaan van die Christelike kerk in die wêreld is die bewys dat die nuwc wêreld reeds aangebreek het; maar die kerk kan nog nie voluit dit wees, waartoe dit bestem is nie. Dit bring mee dat die kerk in die wêreld in voortdurende spanning leef tussen dit wat die kerk deur Gods genade bestem is om te wees, maar nog nie is nie. Die kerk is op pad na die koninkryk, na die voleinding toe. Daarom kan die kcrk in hierdie spanning tussen die nou-al en die nog-nie, in sy op pad. wees so moeilik met menslike taal en definisies duidelik beskryf word.

Nou is dit opmerklik dat die N.T. self ook nie gretig is om duidelike cn noukeurige definisies van die kerk te gee nie. Veeleer gebruik die N.T. daaroor 'n groot aantal beelde en gelykenisse, waardeur die kerk uan in sy verskillende fasette omskryf word. Dis voldoende om van hulle hier net enkeles te noem :

a. Die woord ekklésia wat dikwels in die N.T. gebruik word as die aanduiding van die Christelike kerk, is in hierdie betekenis afkomstig uit die Septuaginta, d.i. die Griekse vertaling van die O.T., waar dit die vertaling is van die hebreeuse woord: qáhal. Die woorde: qáhal Jahwe beteken die saamgeroepe gemeente van die Here in die Ou Verbond. So word nou in die N.T. ckklésia gebruik om die godsvolk van die Nuwe Verbond aan te dui as die gemeenskap van Christusgerowiges wat deur God saamgeroep is, wat uit die wêreld uitgeroep is deur God as sy eiendom en vir sy diens.

b. Ons woord "kerk" is waarskynlik afkomstig van die griekse woord: kuriaké, wat beteken : die Here s'n, dit wat Syne is, Dit sê vir ons dat die kerk die eiendom van die Here is, die gemeenskap waarin Christus as die Kurios, as die Heer alléén regeer deur sy Woord en Gees, - die gemeenskap waarin die Here se wil dié wet is.

c. Die woord "heiliges" word baie dikwels in die N.T. gebruik om 
die kerk, die gemeente of die gelowiges aan te dui. En in hierdie benaming "die heiliges" word die kerk geteken as die gemeenskap van Christusgelowiges wat deur God geheilig is, d.i. afgesonder is deur God, - afgesonder uit die wêreld, afgesonder vir God, as sy eiendom en vir sy diens.

d. 'n Baie bekende beeld vir die gemeente van die Nuwe Verbond is die beeld van die godsvolk. En met hierdie beeld van die godsvolk sluit die N.T. aan by die woorde waarmee in die O.T. die verkiesing, die roeping en heiliging van die godsvolk van die Ou Verbond beskryf word. Ons dink aan tekste soos Lev. 19:2; Ex. 19:5, 6 en Deut. 7:6, 7. As I Petr. 1:15, 16 nou sê : „Maar soos $\mathrm{Hy}$ wat julle geroep het, heilig is, moet julle ook in julle hele lewenswandel heilig word, omdat daar geskrywe is : Wees heilig, want $\mathrm{Ek}$ is heilig ", dan wil I Petr. hier met die woorde van Lev. 19:2 sê dat die Christelike gemeente die ware godsvolk van die Nuwe Verbond is. So word ook in I Petr, 2:9, 10 die Christelike gemeente met die gebruik maak van ou-testamentiese woorde beskrywe as ,'n uitverkore geslag", ,'n koninklike priesterdom", ,'n heilige volk", „'n volk as eiendom verkry". Dit gaan hier dus nie om die roeping, verkiesing en heiliging van vroom eenlinge, van indiwidue los van die gemeenskap van die kerk nie, maar om die heiliging van die hele kerk deur die offer van Christus. En as in Hebr. 4; Kol. 1:12; Hand. 20:32; 26:18 die gemeente gesien word as die godsvolk wat op pad is na die beloofde land, om dit erflik in besit te gaan neem, dan word in hierdie beeldspraak vir ons gesê dat die kerk dié gemeenskap is wat die voleinding van die Godsryk verwag en tegemoet gaan, en dat dit die gemeenskap is wat deur die Heilige Gees as die Voleinder ingelei word in die erfenis van die beloofde saligheid.

\section{Die Eenheid van die kerk.}

Nadat ons enkele aanduidinge gegee het van wat die kerk is, moet nou gevra word na die eenheid van die kerk. Die spanning tussen die nou-al en die nog-nie van die kerk, terwyl dit nog in hierdie wêreld is, kan veral ten opsigte van die eenheid van die kerk besonder sterk en pynlik wees. As die kerk gesien word as die godsvolk wat as geheel deur God geroep en geheilig is, - en as die hele kerk maar net één diens het, nl. om boodskappers van God aan die wêreld te wees, - as die kerk net een Heer het, en sy wil alleen in die kerk geld, - as die kerk as geheel op pad is na één en dieselfde bestemming, nl. die voleinding van die Godsryk, dan kan verwag word dat die eenheid van die kerk duidelik aan die dag sal tree, en vanselfsprekend sal wees. Maar tog staan hierd:e verwagting skynbaar in skerp kontras en spanning 
met die impiriese werklikheid van die kerk in die wêreld, soos dit be. staan in 'n veelheid van kerke, en in 'n verskeidenheid van kerkorganisasies, liturgie, leer en belydenis. Dit laat ons vra : Wat is die eenheid van die kerk waarvan die N.T. praat? Waarin bestaan dit? Hoe word dit bevorder en verwesenlik?

As primêre moet vóórop gestel word dat die eenheid van die Christelike kerk in die drieënige heilige God self rus. As ons glo dat daar éen heilige algemene kerk is, dan is dit nie geloof in iets naas God wat sonder Hom 'n innerlike eenheid of 'n uiterlike organisatoriese eenheid kan besit nie, maar dis geloof in God wat deur die offer van Christus Sy kerk as geheel geheilig het, afgesonder het as sy eiendom, en wat hierdie heiliging verwerklik en voleindig deur die Heilige Gees, sodat die eenheid van die kerk is die drieënige God veranker en gegee is. Dit rus in die ,één Gees, één Here, één God en vader van almal”, Ef. $4: 3-6$. God het aan die gemeente sy cenheid geskenk in Christus, die Hoof, Ef. 4:15, 16, waarvan die gemeente die liggaam is. I Kor. 12:27. Dié eenheid van die kerk vind in die gelykenis van die liggaam 'n treffende uitdrukking : Christus die Hoof kan net één liggaam hê. Maar ook die hegte, onderlinge eenheid van die kerk, die eenheid langs horisontale lyn, ook dit is nie mensewerk nie, maar ook dit rus in Christus die Hoof „uit wie," (volgens Ef. 4:16) „,die hele liggaam sy saambinding en saamvoeging en groeikrag ontvang".

Dat die Christelike kerk sy eenheid in Christus vind, word ook uitgespreek in die gelykenis van die wingerdstok en die ranke, Joh. 15: lvv, -.. maar ook in die beeld van die huwelik, 2 Kor. 11:1, 2 en in die verhouding van die bruidegom tot sy bruid, 'n verhouding waarin die bruidegom met die ywer van sy heilige liefde waak oor die bruid, wat as sy enigste bruid vir Hom afgesonder word, om alleen aan Hom te behoort, (Joh. 3:29; Openb. 21:29; 22:17). Die eenheid word vir die enkele lid van die gemeente verwerklik by sy doop, deurdat hy deur dic Heilige Gecs inbetrek word in dié werklikheid dat Christus sy gemeente as geheel vir Hom geheilig het. Deur die doop word hy ingelyf in die liggaam van Christus, I Kor. 12:13: „Want ons is almal ook deur één Gees gedoop tot één liggaam, . . . . . en ons is almal van éésı Gees deurdronge".

\section{Eenheid en Verskeidenheid.}

Hierdie eenheid van die kerk wat in die drieënige God gefundeer is, sluit egter nie alle verskeidenheid uit nie. Dit vereis nie 'n uiterlike organisatoriese eenheid nie, of 'n eenstemmigheid of enersheid in alle sake nie. Die eenheid bestaan nie, soos die R.K. kerk dit vereis, in 'n absolute organisatoriese uniformiteit nie, maar veeleer daarin, om dié eenheid van dié Gees te bewaar deur die band van die vrede, Ef. 4:3; I Kor. 12:12,13. Dis die eenheid van die geloof en 'n eenheid 
van die kennis van die Seun van God. Ef. 4:13. Daarom sal die cenheid van die kerk die beste gedien word, nie deur 'n uiterlike uniform: teit te propageer en kerkvereniging te organiseer nie, maar deur steeds dieper deur te dring in die betekenis van die Christclike geloof. As die innerlike eenheid van die Gees en van die geloof ontbreek, kan dit deur niks anders vervang word nie. 'n Eenheid wat niks anders is as 'n eenheid in uiterlike vorme nie, is in die grond van die saak 'n illusie wat nooit tot werklikheid eenheid en gemeenskap lei nie. Die na streef van 'n uiterlike uniformiteit as eenheidsideaal, sal die kerk nie sterker en ryker makk nie, maar armer. Want hier dreig die gevaar dat mens met 'n uiterlike uniformiteit tevrede kan wees, en terwille daarvan geestelike dinge kan opoffer. Dit kan wees dit mens dan die oë gaan sluit vir werklike bestaande verskille tussen kerke, en 'n uniformiteit gaan probeer bou op ' $n$ veronderstelde cenheidsfondament wat daar nie is nie. As die eenheid van die kerk hierdie uiterlike uniformiteit sou beteken, sou die R.K. kerk ons die naaste an daardie ideaal bring. Tereg sê Gustav Aulen hiervan in sy boek: Ons Algemeen Christelijk Geloof, bls. 358: „Van dit standpunt gezien blijkt de Roomsche kerkgemeenskap, die geen andere wegen tot Christelyke eenheid kent dan dezen, dat de andere kerkgemeenschappen zich onderwerpen aan den paus en opgaan in de Roomsche kerk, de meest anti-algemene, anti-katholieke van alle Christelyke kerkgemeenschappen te zijn."

Die eenheidsideaal van die N.T. is nie hierdic alles-omvattende uniformiteit nie. Inteendeel het die N.T. oog en waardering vir "n verskeidenheid in die één kerk. So is die verskeidenheid en die werk. verdeling waarvoor die oudste kerk ruimte moes mak, nie gesien as 'n bedreiging van die eenheid van die kerk nie, maar is die eenheid juis beseël deur 'n werkverdeling, vgl. Hand. 15. Soos die verskeidenheid van lede in 'n menslike liggaam hulle lewende eenheid in die liggaam vind, so vind al die lede van die Christelike kerk, in hulle grootste verskeidenheid, (Jode, Grieke, slawe, vrymanne, man en vrou, I Kor. 12:13; Gal. 3:27, 28; Kol. 3:11) hulle eenheid in Christus die Hoof. So deel dieselfde Gees aan die verskillende lede verskillende gawes uit, alles met die oog op wat nuttig is vir die gemeente, (I Kor. 12:7) sodat hulle mekaar daarmee mag dien soos goeie bedienaars van dic veelvuldige genade van God, I Pet. $4: 10$. In die verskeidenheid lî juis die verpligting tot onderlinge hulpbetoon, in die gemeenskap van die liefde, net soos die verskillende lede van die liggaam mekaar nodis: het, en mekaar help en aanvul, juis omdat hulle verskillend is. Hierdie onderlinge hulp en aanvulling wat van toepassing is op indiwiduele gelowiges onderling, is ook waar in die verhouding van kerke. Saam vorm hulle die liggaam van Christus, wat hulle eenheid vind in Christus hulle Hoof, Ef. 4:15, en in die één Gees van wie hulle almal deurdronge is. 


\section{Die Algemeenheid van die Kerk.}

Omdat die cenheid en die algemeenheid van die kerk nie van mekaar losgemaak kan word nie, moet hier ook iets gesê word van die algemeenheid van die kerk. Soos die eenheid van die kerk in die crieënige God veranker is, so rus ook die algemeenheid, die katolisiteit, die universele omvang van die kerk in God, in sy universele liefde vir die wêreld.

In die Ou Verbond het God sy volk as geheel geroep en geheilig, hulle afgesonder uit die volkere van die aarde om sy eiendomsvolk tz wees, vgl. Deut. 7:5, 7; Ex. 19:5, 6. Hierdie afsondering vir God het betrekking gehad op die hele volk Israel. Want volgens Lev. 19:2 ŝe God vir Moses: „Spreek met die hele vergadering van die kinders van Israel en sê vir hulle : Heilig moet julle wees, want Ek die Here julle God is hcilig". Deur die roeping van die hele godsvolk van die Ou Verbond het die grense van die Ou Testementiese heilsgemeente saamgeval met die Israelietiese volksgemeenskap. Hierdie gemeente van die Ou Verbond was dus beperk binne die grense van Israel; en Isracl moes as heilige volk sy afsondering van die volkere, die heidene, die gojjîm bewaar. En dié seremonieël-kultiese heiligheidsbepalinge by. die heilige ban moes dien om Israel as heilige volk drasties af te grens van die onrein heidene. Hierdie ban het gedien as 'n „middelmuur van skeiding" tussen Israel en die heidene, Ef. 2:14. Israel moes sy heilig. heid bewaar in sy afsondering van die volkere.

Maar die Nuwe Verbond het dit anders geword. Deur sy offer het Christus vir Hom 'n nuwe volk geheilig wat die plek van die gods. volk van die $\mathrm{Ou}$ Verbond ingeneem het. So word nou die Christelike gemeente as die nuwe godsvolk genoem : "die Israel van God", ,'n uitverkore geslag", „'n heilige volk", 'n ,heilige nasie”, „'n volk as eiendom verkry", vgl. Ex. 19:5 6; I Petr. 2:9, 10. Maar hierdie nuwe godsvolk het algemeen, universeel geword, deurdat dit nie tot Israel beperk bly nie, maar ook heiden-Christene insluit. Want deur die offer van Christus is die seremonieël-kultiese heiligheid vervul en afgelê. Ook die ban as drastiese afsonderende grens tussen Israel en die heidene, wat Paulus in Ef. 2:15 "vyandskap" noem, het opgehou om te bestaan, omdat die middelmuur van skeiding tussen Israel en die heidene afgebreek is deur die bloed van Christus, Ef. 2:13,14. So he ook die heidene tocgang gekry' tot die godsgemeenskap, en het dic Christelike kerk universeel, algemeen geword. Ook die algemeenheid van die kerk rus dus in die offer van Christus. Hierdie algemeenheid van die kerk verduidelikheid Paulus in verskillende beelde in Ef. 2:15 vv. : Christus het "die middelmuur van skeiding" en die "vyandskap" tussen Jood en heiden deur sy kruis weggeneem, sodat Hy Jode en heidene in Homself tot één liggaam met God versoen deur die kruis, Ef. 2:16. Hy 
het aan albei deur één Gees toegang tot die Vader gegee, Ef. 2:18. Deur die bloed van Christus het hulle wat heidene was (tá ethné) nou die volk van God geword, (laós tou theou, Ef. 2:11). Die verskil tussen Jood en heiden is in die Algemene kerk so seer oorwin dat I Petr. 2:9 dir woorde heiden en volk (ethnos en laos) naasmekaar as sinonieme kan stel, om die godsvolk van die Nuwe Verbond te beskrywe. Die algemeenheid van die Christelike kerk rus dus in God wat die Vader van alle gelowiges is, Gal. 3:26; dit rus in sy universele liefde, liefde vir die wêreld, waardeur $\mathrm{Hy}$ sy Seun oorgegee het, sodat elkeen wat in Hom glo, die ewige lewe kan hê, Joh. 3:16. Nou is hulle almal één in Hom, of hulle Jode of Grieke, slawe of vryes is, één in Hom wat uit al die stamme en tale en volke en nasies ' $n$ volk vir God met sy bloed gekoop het, Openb. $5: 9$.

Die algemeenheid van die Christelike kerk het reeds hierin tot uitdrukking gekom, dat die uitstorting van die Heilige Gees, as eenmalige beslissende openbaringsdaad van God,nie beperk is tot die Pinkstergebeure vir die Jode, wat in Hand. 2 beskryf is nie, maar sig ii verskillende fases voltrek het, sodat dit duidelik kan wees dat die Heilige Gees as die ewige lewe nie alleen vir die Jode bedoel is nie, maar ook vir die veragte Samaritane (Hand. 8) en vir die heidene, (Hand. 10, 11). God self het hiermee die heidene betrek binne die kring van sy heilige gemeente, deur ook aan hulle die Heilige Gees to skenk, - deur dit ook vir Samaritane en heidene Pinkstere te laat word, Hand. 10:45, 47; 11:17, 18.

Ook in Joh. 17:20v. word in die Hoëpriesterlike gebed die eenheid en die algemeenheid van die Christelike kerk beklemtoon, deurdat die bede nie beperk word tot die historiese situasie waarin dit gespreek is nie, maar alle gelowiges van die toekoms insluit. Want as Jesus bid om die eenheid van almal wat deur die prediking in Hom sal glo, dar bid $\mathrm{Hy}$ hier om die eenheid van alle gelowiges oor die hele ruimte en tyd. In die woorde: ,dat hulle ook in Ons één mag wees," bid Jesus nie om 'n uiterlike organisatoriese eenheid nie, maar om 'n geestelike eenheid wat in die Vader en dié Seun rus, 'n eenheid van die geloof aan die Woord, Joh. 17.20v : „Maar Ek bid . . . ook vir die wat deur hulle Woord in My sal glo — dat hulle ook in ons één mag wees!"

\section{Die grense van die kerk.}

As daar nou gevra word na die grense van die universele kerk. dan 1 s dit nie 'n onbedagsame teenspraak nie. Want daarin word ons opnuu: gestel teenoor die pynlike spanning tussen die nou-al en die nog-nie van die kerk, teenoor die feit dat die gemeente van Christus in die wêreld, soos die gemeente van Korinthe, heilige gemeente en tegelyk gemeente 
van sondaars is, - 'n spanning wat alleen in die geloof verduur kan word. As gevolg van hierdie spanning tussen die nou-al en die nog-nie van die kerk, as gevolg van die op pad-wees van die kerk, is die vraag na waar die grense van die kerk lê 'n baie moeilike vraag. As ons die kerk idieël benader, as geestelike begrip, dan kan ons sê dat die grense van die kerk deur die heilige drieënige God self getrek word. Want dit is God self wat sy gemeente heilig, d.i. afsonder as sy eiendom en vir sy diens. Hierdie afsondering deur God, vir Hom en vir sy diens, -- dit is die afgrensing van sy kerk van alles wat nie kerk is nie.

Maar waar presies die grens lê tussen die kerk en wat nie kerk is nie, dit weet die Here alleen. Want alleen die Here ken die wat syne is, I Tim. 2:19. En tog is dit geoorloof en noodsaaklik om te vra na dic grense van die kerk. Dit doen ook die Nederlandse Geloofsbelydenis in Art. 29, waar dit sê : „Ons glo dat met die meeste ywer en versigtigheid uit die Woord van God onderskei moet word wat die ware kerk is". Verder noem Art. 29 ook die hipokriete wat in die kerk onder die goeic vermeng is, en tog nie tot die kerk behoort nie. Die merktekens om die ware kerk te ken, - so gaan die Nederlandse Geloofsbelydenis in Art. 29 voort, - is die volgende : as die kerk die suiwere prediking van die Evangelie uitoefen, as dit die suiwere bediening van die Sakramente gebruik soos Christus dit ingestel het; as die kerklike tug gebruik word om die sondes te straf". Lg. kenmerk is van sekundêre belang in diens van die suiwerc evangelieprediking en die regte Sakramentsbediening.

Omdat ons nie weet waar die grense van die kerk lê nie, moet ons nie vooraf grense trek, om die universele genade van God in die weg te staan en vooraf die grense te beperk nie. Maar ons moet gehoorsaam wees aan die opdrag wat die kerk t.o.v. die wêreld het: „Gaan dan heen, maak dissipels van al die nasies, Matt. 28:19. Gaan die hele wêreld in, en verkondig die Evangelie an die ganse mensdom, Mark. $16: 15$.... En bckering en vergewing van sondes verkondig word aan al die nasies van Jerusalem en verder, Luk. 24:47. . . . En julle sal my getuies wees. . . . . tot aan die uiterste van die aarde". Hand. 1:8.

Andersyds moet ons nic handel asof die kerk geen grense het nie, d.w.s. dat kerk en wêreld nie van mekaar onderskei kan word nie. Die beslissende wat bepaal wie binne en wie buite die kerk is, is nie een of ander menslike norm van afgrensing nie; die beslissende is die geloof in Jesus Christus, Joh. 3:15; Gal. 3:26. Die grens lê tussen geloof en ongeloof. Maar hoe bepaal die kerk dit? Vir die kerk is die enigste praktiese matstaf die inhoud van die geloof. Daarom moet die worsteling om die grense van die kerk gekonsentreer wees, nie op mens, like maatreëls van afgrensinge of menslikc eenheidsmakery van die kerk nie, - maar dit moet gekonsentreer wees op die inhoud van die 
geloof, op die inhoud van die Woord van God, op die ware betekenis van die Evangelie. Die omtrekke, die grense van die kerk is die omtrekke van die liggaam van Christus wat opgebou moet word ,totdat ons almal kom tot die eenheid van die geloof, tot die eenheid van die kennis van die Seun van God, Ef. $4: 13$. Hierdie geloof, hierdie kennis van die Seun van God help nie alleen om die eenheid van die kerk te verwerklik nie, maar dui ook die grense aan. Wie dus nadink oor die grense van die kerk, moet hom besin oor die inhoud van die geloof, oor die leer en die belydenis in die lig van Gods Woord. Om te onderskei wie hierdie geloof opreg bely, en wie dit as hipokriete doen, is vir ons mense nie moontlik nie; dit is God se saak. Die Here ken die wat syne is.

Tereg merk van Niftrik hieroor op in sy Kleine Dogmatiek, bl. 181: „Alleen de Heer kent Zyn Kerk geheel. Daarom zal het een Kerk altyd moeilijk vallen grenzen te trekken. In gebed en bezinning zal de Kerk altyd weer naar haar grenzen moeten zoeken, en wee die Kerk die zoo statisch - welverzekerd precies haar grenzen weet te trekken. Wel moeten er grenzen getrokken worden, maar dit kan alleen geschieden in geloof, met vreeze en beven".

- S. P. J. J. van Renşurg. 